GAPP, número 24, noviembre de 2020

Sección: RECENSIONES

Recibido: 01-09-2020

Aceptado: 15-10-2020

DOI: https://doi.org/10.24965/gapp.i24.10856

Páginas: $147-151$

\title{
Montolío, Estrella y TAscón, Mario: El derecho a entender: la comunicación clara, la mejor defensa de la ciudadanía
}

\section{Montolío, Estrella \& TAscón, Mario: El derecho a entender: la comunicación clara, la mejor defensa de la ciudadanía}

\author{
César Nicandro Cruz-Rubio \\ Grupo de Investigación en Gobierno, Administración y Políticas Públicas - GIGAPP (España) \\ ORCID: https://orcid.org/0000-0002-2881-9056 \\ cesar.cruz.rubio@gigapp.org
}

\begin{abstract}
NOTA BIOGRÁFICA
Licenciado Ciencias Políticas Por la UNAM México (1996). Doctor por la Universidad Complutense de Madrid (2015). Profesor Departamento de Ciencias Sociales de la Universidad Carlos III. Investigador Principal GIGAPP Grupo de Investigación en Gobierno, Administración y Políticas Públicas. Miembro Panel Expertos IRM-OGP. Formador y experto internacional en políticas públicas, transparencia y gobierno abierto.
\end{abstract}

\section{RESUMEN}

Recensión: Montolío, Estrella y TAScón, Mario. El derecho a entender: la comunicación clara, la mejor defensa de la ciudadanía. Madrid: Prodigioso Volcán y Catarata, 2020, 192 págs.

\section{PALABRAS CLAVE}

Comunicación clara; lenguaje comprensible; transparencia.

\begin{abstract}
Review: Montolío, Estrella y TAscón, Mario. El derecho a entender: la comunicación clara, la mejor defensa de la ciudadanía. Madrid: Prodigioso Volcán y Catarata, 2020, 192 pp.
\end{abstract}

\section{KEYWORDS}

Plain communication; plain language; transparency.

¿De qué forma una persona puede reclamar o ejercer sus derechos ante la administración si no entiende los documentos que recibe, no entiende qué se le pide en concreto, o por qué ha sido multado, por ejemplo? ¿Cómo podemos acceder con garantías de igualdad de oportunidades a beneficios, ayudas o a servicios públicos concretos, si no entendemos a quiénes se dirige tales ayudas, quienes son elegibles, a qué se refieren tales instrumentos, cómo se pueden presentarse solicitudes o reclamar? ¿De qué forma se pueden pedir cuentas o exigir responsabilidades a los gobiernos y administraciones por sus actos, cuando los procedimientos legales definidos para ello no son comprendidos con claridad? ¿De qué forma podemos participar libre, plenamente y en igualdad de condiciones en la definición o seguimiento de las políticas o los servicios públicos, si no comprendemos la información que se nos brinda para ello y no entendemos por qué hace lo que hace -y cómo lo hace- el gobierno?

¿Qué es el derecho a entender y por qué es importante?¿Cómo podemos transitar de una comunicación burocrática a una comunicación democrática? En este libro se tratan estas importantes cuestiones y se 
GAPP.NuevaÉpoca - N. ${ }^{2} 24$, noviembre2020 - ISSN:1989-8991 - DOI:https://doi.org/10.24965/gapp.i24.10856 - [Págs. 147-151]

MONTOLÍo, Estrella y TAScón, Mario: El derecho a entender: la comunicación clara, la mejor defensa de la ciudadanía

César Nicandro Cruz-Rubio

brindan respuestas a estas preguntas, tan necesarias y urgentes de abordar hoy en día. Hace ya algunos años escuché por primera vez a mi amigo Joaquín Meseguer (quien entonces fungía como director de Transparencia del Ayuntamiento de Madrid) abordar este tema, en el marco de la valoración de la transparencia en las organizaciones públicas, describiéndolo de esta forma más o menos (y que aquí me permito parafrasear): Junto con el derecho a saber, es igualmente importante del derecho de las personas a entender las acciones y decisiones de sus gobiernos y administraciones públicas, así como materializar este derecho en estrategias de interacción y comunicación eficaces entre la administración pública y los ciudadanos/as.

El libro de Montolío y Tascón avanza en esta línea, y resulta de lectura obligada desde varios frentes disciplinarios, pero, sobre todo, resulta relevante para aquellos/as funcionarios/as públicos, investigadores y/o ciudadanos/as preocupados por mejorar la eficacia, confianza y transparencia de las organizaciones (no importa si son públicas o privadas).

De gran utilidad conceptual, así como con una clara orientación hacia la práctica, este libro ofrece un método, pautas y consejos en materia de uso del lenguaje y comunicación institucional para mejorar la gestión pública, el diseño y la prestación de servicios públicos, y con ello contribuir a un buen gobierno y una buena administración. Por tanto, también es un libro muy relevante para aquellos que, desde sociedad civil, gobierno o academia, están interesados/as en diseñar o analizar servicios y/o políticas públicas que se afianzan en procesos abiertos y participativos.

Por su carácter transdisciplinar, advertimos que este libro podría reseñarse desde varios prismas. En esta reseña ubicaré mi reflexión en el marco del binomio transparencia pública - lenguaje y comunicación clara. En este libro se busca reivindicar a una ciudadanía conocedora de sus derechos y responsabilidades frente a la administración pública. Materializar el derecho a entender supone no sólo ser transparente en la actuación pública, o hacer más cercana la administración a las personas. Se trata fundamentalmente, de garantizar el ejercicio pleno de derechos en todos los planos de la vida individual y colectiva, sin exclusiones, y con ello de avanzar en la democratización del ejercicio del poder. Lograrlo supondría abandonar la idea de aceptar sin más que los gobiernos y administraciones operen sin cuestionamiento como cajas negras, que sólo necesitan hacerse entender o justificarse bien en clave interna o frente a los ciudadanos/as más ilustrados, atendiendo a una jerga y lenguaje especializado, y donde perviven gobiernos que generan productos, servicios y toman decisiones que son transmitidos o comunicados de tal modo que sólo son comprensibles para insiders, técnicos, doctos o iniciados.

Los fracasos gubernamentales en materia comunicacional existen. Algunos de estos también conllevan el fracaso de las políticas. Están aquellos más evidentes o conocidos, ocurridos por fiascos asociados a políticas públicas mal informadas a la ciudadanía. Pero están también aquellos fracasos comunicacionales menos evidentes o visibles, que ocurren a diario y que son más bien asumidos o soportados como parte de una realidad administrativa, francamente mejorable. Nos referimos a los fallos de comunicación asociados a las interacciones cotidianas entre gobiernos y ciudadanos/as, en los servicios públicos, al uso opaco del lenguaje en las mismos y de la ausencia de estrategias para hacer comprensibles los mensajes, información y decisiones administrativas o trámites, lo que impide ofrecer o garantizar el acceso en condiciones de igualdad e inclusión a políticas y servicios públicos. Se trata de la forma en cómo las administraciones se dirigen a las personas, que muchas veces ha ocurrido en ausencia de transparencia, pero también (y fundamental en esta ecuación) en ausencia o deficiencias en el entendimiento.

En este contexto, la transparencia es un valor clave. Más que un fin, la transparencia es un medio para recuperar la confianza en el gobierno y en la administración pública. Es también un medio para atender muchos males que aquejan a nuestras sociedades, en materia de integridad, eficacia y relevancia social. Hoy en día, las presiones económicas, medioambientales y la reciente crisis sanitaria, social y económica mundial provocada por la pandemia del COVID-19, junto con el desarrollo tecnológico asociado al avance del big data, la inteligencia artificial y el Internet de las cosas, sólo han hecho más evidente esta necesidad de avanzar hacia una mayor transparencia en todas las dimensiones de la vida pública. En las democracias actuales, la transparencia ya no es una opción. Como ciudadanos/as, necesitamos conocer y comprender qué decisiones están tomando nuestros gobiernos para proteger nuestras vidas, nuestros derechos y nuestras libertades, y cómo las buscan materializar a través de las administraciones públicas. Las democracias actuales han incorporado la transparencia como uno de sus medios y principios clave de actuación. Tanto es así, que dar pasos hacia atrás en materia de transparencia supone hoy día hablar de retroceso democrático.

Pero transparencia y acceso a la información no implican necesariamente conocimiento o entendimiento. La transparencia y el acceso a la información pública son medios necesarios, pero no suficientes para conocer, entender y comprender las decisiones y acciones del gobierno y su administración. Al igual que la 
transparencia, en este libro se entiende al lenguaje y comunicación claras como medios clave, y que, junto con la transparencia, permiten mejorar la eficacia institucional, generar confianza e incrementar la calidad democrática de las instituciones y sus gobiernos.

La opacidad no sólo ocurre y se perpetúa por la ausencia de información y de transparencia. También ocurre y se perpetua cuando no se entiende lo que hacen las administraciones. Cuando las administraciones no son conscientes de ello y no ponen medios para posibilitar un mayor entendimiento de lo que hace (y por qué lo hace), bajo el alero de argumentos garantistas o formalistas, se renuncia en gran medida a acercar la administración a la ciudadanía. Rigor no significa opacidad o falta de claridad.

Con sus reflexiones, este libro propone ampliar el espacio fundamental de la transparencia pública, y avanzar con ello en la apertura de los gobiernos y administraciones. Pero también se refiere a hacer más entendible el papel e importancia de las acciones de las organizaciones (sean públicas o privadas), sus procesos clave y sus servicios en la vida cotidiana de las personas. Su propuesta en definitiva trata de identificar el camino y el necesario tránsito del derecho a saber al derecho a entender, al que todas las sociedades democráticas deben enfrentar tarde o temprano, en mayor o menor medida.

Hacerse entender es una responsabilidad de los gobiernos y sus administraciones, sobre todo en las decisiones administrativas consideradas fundamentales (o muy relevantes) para la vida de las personas. Lamentablemente, no son pocos los casos donde esta necesidad no es entendida como tal por las administraciones, y donde son otros actores, tales como las OSC o ciudadanos de a pie quienes se preocupan de ello y ofrecen soluciones para hacer más clara y entendible la información que generan las administraciones públicas (véase, por ejemplo, para el caso español, el trabajo que la OSC Civio realiza con su proyecto "el BOE nuestro de cada día", entre otros proyectos asociados a esta cuestión).

La experiencia asociada a la interacción administrativa cotidiana da cuenta que con acceder a la información no es suficiente. Al persistir opacidad asociada a la falta de claridad de la información, y no tanto en la falta de información o de acceso a la misma, también se favorecen injusticias o se perpetúan exclusiones en varios niveles. Por tanto, la falta de claridad no sólo va en contra de la transparencia, sino que también atenta contra la inclusión y la igualdad.

Al igual que el derecho de acceso a la información, el derecho a entender es un derecho transversal y habilitante de otros derechos. Sin duda, la ausencia de claridad no favorece el desarrollo de una cultura de transparencia y rendición de cuentas, y puede tener enormes repercusiones en la eficacia y calidad democrática de nuestros gobiernos y sus administraciones, minando la confianza, poniendo incluso en entredicho el rol de Estado como regulador y redistribuidor eficaz de la riqueza en los estados democráticos y sociales de derecho, y con ello, su legitimidad basada en rendimientos.

La alternativa que se vislumbra cuando los gobiernos no avanzan o garantizan el derecho a entender es bastante sombría. Como principales consecuencias identificables podríamos enumerar: a) la indefensión ciudadana frente al gobierno y sus administraciones; b) el subejercicio de derechos ciudadanos, condenándolos de facto a aquellos que no comprenden a perpetuarse como ciudadanos «menores de edad», sobre todo en aquellos colectivos en riesgo de exclusión; c) el uso excesivo o no justificado de intermediarios «ilustrados» entre las administraciones y los ciudadanos, que elevan y justifican la tramitología, el burocratismo y los costos de transacción algunas veces económicamente no asumibles (por interactuar con la administración) por las personas; d) la posibilidad de un ejercicio discrecional sin freno del poder administrativo, ocultado por nubes de tecnicismos procedimientos poco claros y lenguaje legal erudito; e) procesos participativos que propician nuevas formas de exclusión, o que facilitan procesos legitimadores de decisiones previamente tomadas, antes que proceso inclusivos o que habilitan procesos deliberativos plenos. Como se puede advertir, algunas de estas consecuencias negativas podrían alimentarse entre sí favoreciendo procesos de feedback positivo.

En ausencia de este derecho, se perpetúa la existencia de un divorcio de facto entre gobernantes y gobernados, conveniente para una parte cuando se trata de mantener una situación de privilegio o poder, o generar desigualdades entre distintos colectivos por asimetrías en la comprensión de información, no justificables ni legal ni democráticamente, y que, dicho sea de paso, también pueden permitir la conformación de espacios y oportunidades para la corrupción. La cuestión más relevante es que, en ausencia de claridad, no todos los ciudadanos/as pierden de igual forma. Los que no logran entender a las administraciones pueden perder mucho, mucho más.

Bajo una narrativa fluida y clara (como no), el libro de Montolío y Tascón ofrece a los/as lectores una muy completa reseña en la identificación del derecho a entender en la normativa (con énfasis en la normativa española y europea). Como los autores advierten, se trata de un derecho que, aunque indicado o advertido en varias normativas, no se encuentra sustanciado en una ley específica. 
Aunque el libro organiza su contenido en siete capítulos, el lector o lectora tal vez pueda identificar dos grandes partes. La primera parte, que llamaremos aquí «entender el derecho a entender» la comprenden los primeros tres capítulos. Esta parte nos ofrece un repaso histórico por este derecho (capítulo I), pasando por el movimiento importante Plain English movement que avanzó en el mundo anglosajón, y que caló en Europa con posterioridad, y donde los pasos se dieron claros avances en algunos países escandinavos, para pasar con posterioridad al contexto iberoamericano. El libro realiza un repaso ilustrador e interesante (capítulo II) respecto de los retos que plantean las tecnologías de la información y la comunicación sobre este tema, vinculando tópicos tan útiles como actuales tales como la experiencia de los usuarios (UX), el diseño de contenidos, y la importancia de incluir el derecho a entender desde el principio, en decir, la fase de diseño de cualquier política o proyecto tecnológico de gobierno, considerando la diversidad, pasando por los productos y servicios inclusivos asociados al desarrollo web, apps y en general de cualquier recurso virtual. Ahora bien, con el avance de la inteligencia artificial y el machine learning, es fundamental garantizar que el uso de estas tecnologías se asienta sobre valores éticos, cuenten con permanente revisión para garantizar el cumplimiento de los principios de accesibilidad e inclusión. El capítulo III cerraría esta primera parte, y da cuenta con profundidad sobre el avance del derecho a entender la información jurídica en España y al nivel internacional, revisando a tal fin la normativa en diversas materias (transparencia, protección del consumidor, derecho civil y penal, protección de datos personales, acceso a la justicia, dando cuenta brevemente de la experiencia de algunos países iberoamericanos).

La segunda parte, que podríamos denominar «materializar el derecho a entender» comienza desde el capítulo IV, cuando los autores buscan reivindicar el lugar de las personas como el centro de todo esfuerzo comunicacional, destacando la calidad, simpleza y la información en entornos digitales, la necesidad de que los usuarios digitales pasen a ser entendidos como ciudadanos digitales, con derechos y obligaciones, ofreciendo una nutrida y atinada relación de elementos clave para la escritura clara, basada en la simplicidad y en la definición de estructuras claras. Posteriormente (capítulo V), profundiza en esta cuestión, ofreciendo pautas para una escritura clara, haciendo especial referencia a la escritura en los entornos digitales, donde el tipo de plataforma define el contenido, y abordando con profundidad la experiencia de los usuarios, los diseños universales e inclusivos, así como cuestiones clave relacionadas con la accesibilidad. El capítulo VI entra de lleno en el cómo lograr este cambio, es decir, cómo potenciar cambios vinculados a la comunicación clara en las organizaciones públicas, recuperando a tal efecto (como caso) la experiencia participativa del Ayuntamiento de Madrid, y donde se destaca que, para ser exitosos, estos procesos exigen apertura desde el comienzo. No son procesos que puedan articularse sin las personas implicadas o afectadas, pues «... para promover una comunicación clara es preciso transformar la cultura comunicativa, orientarla hacia las necesidades de las personas en toda su diversidad» (Montolío y Tascón, 2020 pág. 135).

El último capítulo recupera una guía de nueve pasos para avanzar hacia una comunicación clara. Este modelo o guía fue ideado y publicado en trabajos previos de los autores, como medio para facilitar la transferencia de conocimiento experto en la materia. Los nueve pasos incluyen una secuencia lógica de actividades en clave de proceso iterativo para la transformación de una estrategia de comunicación hacia lenguaje y comunicación clara, donde es preciso planificar e identificar los objetivos, editar los textos resultantes, completar la información, añadir imágenes, diseñar el producto o servicio, añadir recursos gráficos, o interactivos (también llamados hipermediables), para potenciar la interactividad y considerar la experiencias del usuario, y finalmente, revisar y comprobar los contenidos, productos y mensajes.

Así pues, el libro de Montolío y Tascón no es sólo un libro sobre el derecho a entender. Tampoco es sólo un libro centrado en dar pautas para mejorar la comunicación administrativa. Se trata más bien de un libro que aborda un tópico transversal y complejo como éste, desde un enfoque igualmente transversal, introduciendo así al lector/a con éxito en este importante tema y ofreciendo algunas pautas y una guía de actuación para mejorar y hacer más claro el lenguaje y la comunicación de las administraciones públicas.

Como se ha dicho ya, la parte final del libro brinda herramientas estratégicas (cuyo valor añadido está en el carácter contrastado de las mismas) para la materialización de este derecho. El uso generalizado de esta metodología, y otras similares también referidas también en el libro, puede contribuir sin duda a avanzar en este derecho, y con ello, favorecer también el pleno ejercicio de los derechos ciudadanos frente a la administración y al fortalecimiento de la gobernanza pública más democrática e incluyente.

En mi opinión, tal como con la transparencia y el derecho a saber ha ocurrido en muchos países del mundo, el derecho a entender y la garantía de uso de un lenguaje y comunicación claras deberían llegar para quedarse, esto es, ser consolidados y entendidos como principios o valores clave de la vida colectiva. En este escenario ideal, cualquier retroceso en esta dimensión debería considerarse un retroceso en la 
transparencia y en la calidad democrática de nuestras administraciones públicas. Para lograr llegar a este escenario, el derecho a entender debería consolidarse como principio transversal no sólo en la norma, sino en todos los niveles de la vida política y administrativa, en el discurso público e ideario colectivos. Debería ser monitorizado continuamente mediante sistemas de indicadores y ser entendido como una parte indispensable asociada a la eficacia administrativa (es decir, entender que sin claridad en el uso del lenguaje y en la comunicación no puede hablarse de eficacia asociada a políticas, trámites o servicios públicos), como elemento consustancial a la transparencia pública (acceder a la información no basta, y sin claridad no es posible hablar de calidad de la transparencia pública), y como un indicador irrenunciable para medir la calidad democrática de nuestras sociedad (la claridad comunicativa como criterio de valoración de un buen gobierno y buena administración).

Una mejor, más transparente, cercana, eficaz e inclusiva interacción entre gobiernos y ciudadanos, no puede sino pasar por garantizar el uso de un lenguaje y comunicación claras. Hoy en día, la opción de no avanzar se antoja anacrónica, excluyente, además de incoherente en nuestras democracias contemporáneas. El libro de Montolío y Tascón busca allanar este camino, pues hay mucho por andar y hay mucho también en juego si decidimos no emprender con decisión la marcha. 